\title{
EROSÃO HÍDRICA EM PLANTIO DE PINUS, EM ESTRADA FLORESTAL E EM CAMPO NATIVO
}

\author{
Luciane Costa de Oliveira ${ }^{1}$, Ildegardis Bertol², Mari Lúcia Campos², José Mecabô Júnior ${ }^{3}$ \\ ${ }^{1}$ Eng $^{\mathrm{a}}$. Agrônoma, Dr ${ }^{\mathrm{a}}$., IFSC, Lages, SC, Brasil - luciane.costa@ifsc.edu.br \\ ${ }^{2}$ Eng. Agrônomo, Dr., Depto. de Solos, CAV, UDESC, Lages, SC, Brasil - a2ib@cav.udesc.br; a2mlc@cav.udesc.br \\ ${ }^{3}$ Eng. Agrônomo, Mestrando em Manejo do Solo, CAV, UDESC, Lages, SC, Brasil - jose.mecabo@ifsc.edu.br \\ Recebido para publicação: 04/04/2013 - Aceito para publicação: 18/11/2013
}

\begin{abstract}
Resumo
Santa Catarina é o terceiro exportador de produtos florestais, com 320 mil ha (11\%) das florestas plantadas brasileiras. Somente na região de Lages, SC, existem 70 milhões de árvores de pinus plantadas, o que faz dessa região a terceira do mundo em área florestada com essa espécie, atrás de Finlândia e Suécia. O trabalho objetivou quantificar a erosão hídrica durante 17 meses (entre setembro de 2009 e janeiro de 2011), sob chuva natural, em reflorestamento de pinus com diferentes idades, em uma estrada de uso florestal e em campo nativo, no município de Campo Belo do Sul, SC, na empresa "Florestal Gateados" Ltda., em que a enxurrada foi coletada com uma Roda Coshocton. As perdas de água por escoamento superficial foram de $6 \mathrm{~mm}$ no pinus de três anos, de $13 \mathrm{~mm}$ no campo nativo, de $23 \mathrm{~mm}$ no pinus de 10 meses e $157 \mathrm{~mm}$ no pinus de 26 anos, consideradas muito baixas em relação à precipitação ocorrida no período experimental, que foi de $2.040 \mathrm{~mm}$, enquanto que na estrada florestal as perdas de água foram de $928 \mathrm{~mm}$, consideradas altas. Quanto às perdas de solo, elas foram de $8 \mathrm{~kg} \cdot \mathrm{ha}^{-1}$ no pinus de três anos, $28 \mathrm{~kg} \cdot \mathrm{ha}^{-1}$ no campo nativo, $40 \mathrm{~kg} \cdot \mathrm{ha}^{-1}$ no pinus de 26 anos e 74 kg.ha ${ }^{-1}$ no pinus de 10 meses, também consideradas muito baixas em relação à tolerância de perda de solo, enquanto que na estrada florestal as perdas de solo foram de $22.000 \mathrm{~kg} . \mathrm{ha}^{-1}$, consideradas altas.

Palavras-chave: Perdas de solo e água; Roda Coshocton; reflorestamentos.
\end{abstract}

\begin{abstract}
Hidric erosion in pinus culture, in forestry road and native grassland. Santa Catarina is the third Brazilian state in exporting forestry products, with 320,000 hectares (11\%) of Brazilian forests. Only in Lages there are 70 millions of pinus trees, and it is the third region with the greater density forested area in the world, just losing to Finland and Sweden. This research had as objective to quantify rainfall erosion during 17 months (from September, 2009 to January, 2011), under natural rain, in pinus reforestation areas with different ages, in a forestry road and natural grasslands, in Campo Belo do Sul/SC - Florestal Gateados Ltda., where the runoff was collected by Coshocton wheels. Water loss by runoff was $6 \mathrm{~mm}$ for three years-old pinus, $13 \mathrm{~mm}$ for natural grasslands, $23 \mathrm{~mm}$ for ten months-old pinus trees and $157 \mathrm{~mm}$ for 26 years-old pinus; all of them were considered small due to the rainfall which occurred during the experiment period $(2.040 \mathrm{~mm})$; however, in the forestry road, water loss was considered higher $(928 \mathrm{~mm})$. In relation to soil losses, those were $8 \mathrm{~kg} \cdot \mathrm{ha}^{-1}$ for three years-old pinus, $28 \mathrm{~kg} \cdot \mathrm{ha}^{-1}$ for natural grasslands, $40 \mathrm{~kg} \cdot \mathrm{ha}^{-1}$ for 26 years-old pinus and $74 \mathrm{~kg} \mathrm{ha}^{-1}$ for ten months-old pinus trees; all of them were considered small in relation to the tolerance of soil loss; however, in the forestry road, soil loss was considered higher (22.000 kg.ha-1).

Keywords: Soil and water losses; Coshocton weels; reforestation.
\end{abstract}

\section{INTRODUÇÃO}

Muitas propriedades de produção florestal desenvolvem suas atividades em terrenos nem sempre compatíveis com a aptidão de uso da terra. As técnicas de manejo do solo, em especial as práticas de colheita, o transporte da madeira e a própria espécie cultivada podem não serem as mais apropriadas para um determinado local. Os reflexos disso recaem diretamente sobre o ambiente, sendo que um dos principais efeitos negativos observados é a degradação do solo e da água pela erosão hídrica (STOLLE, 2007). Algumas das operações de manejo da floresta, especialmente a colheita, resultam na remoção de 
resíduos superficiais e revolvimento do solo, tendo como consequência a eliminação de massa vegetal que poderia cobrir o solo, um importante fator de controle da erosão hídrica pluvial. Nesses casos, a erosão pode chegar a remover uma profunda camada do solo, às vezes até todo o horizonte "A", no caso das estradas florestais. As perdas de solo e água por erosão têm importantes implicações sobre a fertilidade, particularmente porque as camadas superficiais são as mais férteis e as primeiras a serem erodidas. Alguns aspectos do plantio e do manejo de uma floresta, tais como o espaçamento entre plantas e a frequência de desramas e desbastes, influenciam na quantidade de massa vegetal sobre a superfície e, consequentemente, na cobertura do solo durante o crescimento das árvores.

A forma de uso da terra atualmente empregada nos cultivos de pinus no Brasil tem causado a degradação do solo, devido aos ciclos ininterruptos da cultura e adoção de operações de manejo não conservacionista de solo. No setor florestal, a adoção de métodos de preparo do solo inadequados para a implantação da floresta, principalmente abertura de sulcos na direção da pendente do terreno, com revolvimento excessivo, gera erosão especialmente nos períodos de altas precipitações pluviométricas. A colheita mecanizada realizada de forma inadequada, com redução da cobertura superficial e aumento da compactação do solo, diminui a infiltração de água no solo e aumenta a enxurrada. A locação inadequada da rede viária, com problemas associados à captação e condução de água da chuva e consequente deságue de enxurrada concentrada em áreas fragilizadas do terreno, também potencializa a erosão. Isso tem ocasionado erosão, principalmente em sulcos, podendo a mesma evoluir para voçorocas, tanto nas estradas quanto nos talhões adjacentes (CAVICHIOLO, 2005). Devido a isso, o preparo intensivo do solo para implantar o reflorestamento e o manejo inadequado posterior podem reduzir sua capacidade produtiva no longo prazo. Isso ocorre principalmente pelos processos de compactação do solo, lixiviação e/ou volatilização de nutrientes e perdas, via erosão hídrica pluvial, de água, solo, nutrientes e matéria orgânica (PYE; VITOUSEK, 1985).

Este trabalho objetivou quantificar a erosão hídrica durante 17 meses, sob chuva natural, em reflorestamentos de pinus com diferentes idades, campo nativo e em uma estrada florestal.

\section{MATERIAL E MÉTODOS}

O trabalho foi realizado em campo, na fazenda da empresa "Florestal Gateados Ltda.", situada no município de Campo Belo do Sul, SC, a 67 km do município de Lages, durante o período de setembro de 2009 a janeiro de 2011. O clima da região é mesotérmico úmido, classificado como Cfb segundo Köppen (1948), com temperatura variando de 13 a $25{ }^{\circ} \mathrm{C}$ e com chuvas distribuídas durante todo o ano, totalizando, em média, $1.800 \mathrm{~mm}$ anuais (GOVERNO DE SANTA CATARINA, 2013). A altitude média da região é de $1.017 \mathrm{~m}$ e o relevo é ondulado.

Os locais das parcelas experimentais, sem repetição, foram escolhidos para contemplar quatro condições: reflorestamento de pinus com três idades, campo nativo e estrada florestal. Por isso, as parcelas foram instaladas em locais distintos dentro da fazenda e cada uma delas constituiu um tratamento. Na parcela I havia pinus plantado em novembro de 2008, tendo 10 meses de idade na data de instalação do trabalho (Pi10m). O plantio foi feito sobre uma área na qual havia sido cultivado pinus durante aproximadamente 30 anos, o qual havia sido colhido recentemente de forma semimecanizada, e forma que restavam pedaços de madeira e tocos do cultivo anterior. A área da parcela era de $239 \mathrm{~m}^{2}$ e apresentava $6 \%$ de declividade. Continha 39 árvores com altura inicial de $50 \mathrm{~cm}$, as quais, ao término do trabalho, em janeiro de 2011, estavam com 3,1 $\mathrm{m}$ de altura e $5 \mathrm{~cm}$ de diâmetro. $\mathrm{O}$ espaçamento das plantas era de $2 \mathrm{~m}$ entre si e 2,5 $\mathrm{m}$ entre as linhas. $\mathrm{O}$ solo na parcela I é um Neossolo Litólico. Na parcela II havia pinus plantado em 1983, tendo 26 anos de idade na data de instalação do trabalho (Pi26a). O plantio foi feito sobre área de campo nativo que vinha sendo pastejado extensivamente por bovinos. A área da parcela era de $278 \mathrm{~m}^{2}$ e apresentava $11 \%$ de declividade. O espaçamento das plantas na época do plantio era igual ao da parcela I. Devido aos desbastes ao longo do cultivo, restaram quatro árvores com altura de $28 \mathrm{~m}$ e $38,5 \mathrm{~cm}$ de diâmetro. O solo na parcela II é um Latossolo Bruno. Na parcela III havia campo nativo característico da serra catarinense (CN). A área da parcela era de 315 $\mathrm{m}^{2}$ e apresentava $16 \%$ de declividade. O solo na parcela III é um Nitossolo Háplico. Na parcela IV havia uma estrada florestal (EF). A área da parcela era de $76 \mathrm{~m}^{2}$ e apresentava $10 \%$ de declividade. O solo na parcela IV era um Nitossolo Háplico. Devido às operações mecânicas de construção e de manutenção periódica da estrada, e ao efeito da erosão, a camada superficial do solo foi totalmente removida, de modo que o leito da estrada situava-se a uma profundidade $0,7 \mathrm{~m}$ do nível original da superfície do solo na época do início do 
experimento. Dessa forma, os dados obtidos nessa parcela são referentes ao horizonte B/A do solo. Na parcela V havia pinus plantado em 2006, tendo três anos de idade na data de instalação do trabalho (Pi3a). O plantio foi feito sobre área de campo nativo. A área da parcela era de $281 \mathrm{~m}^{2}$ e apresentava $16 \%$ de declividade. Continha 55 árvores com altura inicial de $5 \mathrm{~m}$ e 8,8 $\mathrm{cm}$ de diâmetro, os quais, ao término do trabalho, em janeiro de 2011, estavam com 6,6 m de altura e 12,4 cm de diâmetro. O espaçamento entre árvores era igual ao da parcela I. O solo da parcela V é um Nitossolo Háplico.

Na tabela 1 encontram-se algumas características físicas dos solos descritos nos locais das parcelas, nos quais foram abertas trincheiras para descrição dos solos e coletas das amostras. Para determinar a Ma, Mi, PT e Ds, foram coletadas amostras não deformadas, em anéis volumétricos com $5 \mathrm{~cm}$ de altura e $5 \mathrm{~cm}$ de diâmetro, enquanto que, para a determinação de Sil, Arg e Are, coletaram-se amostras deformadas. A porosidade foi determinada com o uso da mesa de tensão. Para os macroporos, utilizou-se a altura de $60 \mathrm{~cm}$ de sucção; para os microporos, a altura de $100 \mathrm{~cm}$ de sucção. A porosidade total foi obtida pela soma de macro e microporos. A textura do solo foi determinada utilizando-se o método internacional da pipeta (GEE; BAUDER, 1986). A densidade do solo foi obtida pela razão entre o peso do solo seco a $105^{\circ} \mathrm{C}$ e o volume do anel no qual o solo foi coletado.

Tabela 1. Valores de macroporosidade (Ma), microporosidade (Mi), porosidade total (Pt), silte (Sil), argila (Arg), areia (Are) e densidade do solo (Ds), nos horizontes A e B dos perfis dos solos estudados.

Table 1. Values of macroporosity (Ma), microporosity (Mi), total porosity (Pt), silt (Sil), clay (Arg), sand (Are) and soil density (Ds) in horizons A and B of soils.

\begin{tabular}{|c|c|c|c|c|c|c|c|}
\hline $\begin{array}{l}\text { Horizonte (profundidade) } \\
\text { cm }\end{array}$ & Ma & Mi & $\begin{array}{l}\text { Pt } \\
---\%\end{array}$ & Sil & Arg & Are & $\begin{array}{c}\text { Ds } \\
\text { g.cm }\end{array}$ \\
\hline \multicolumn{8}{|c|}{ Neossolo Litólico (Pi 10m) } \\
\hline $\mathrm{A} 1(0-13)$ & 4 & 44 & 48 & 32 & 60 & 8 & 1,2 \\
\hline A2 $(13-33)$ & 8 & 49 & 57 & 32 & 61 & 8 & 1,1 \\
\hline $\mathrm{A} / \mathrm{Cr}(33-40)$ & 3 & 49 & 52 & 29 & 43 & 28 & 1,2 \\
\hline \multicolumn{8}{|c|}{ Latossolo Bruno (Pi 26a) } \\
\hline A1 $(0-20)$ & 6 & 47 & 53 & 29 & 65 & 6 & 1,0 \\
\hline A2 $(20-34)$ & 2 & 50 & 52 & 31 & 64 & 5 & 1,2 \\
\hline A/B1 (34 - 47) & 2 & 49 & 51 & 27 & 68 & 5 & 1,3 \\
\hline $\mathrm{A} / \mathrm{B} 2(47-62)$ & 1 & 45 & 46 & 25 & 71 & 4 & 1,1 \\
\hline $\mathrm{B} / \mathrm{A}(62-81)$ & 4 & 46 & 50 & 22 & 74 & 4 & 1,2 \\
\hline BW1 (81 - 133) & 3 & 52 & 55 & 22 & 74 & 4 & 1,2 \\
\hline \multicolumn{8}{|c|}{ Nitossolo Háplico (CN) } \\
\hline $\mathrm{A} 1(0-17)$ & 8 & 45 & 53 & 36 & 58 & 6 & 0,9 \\
\hline A2 $(17-42)$ & 5 & 50 & 55 & 31 & 63 & 6 & 1,2 \\
\hline $\mathrm{A} / \mathrm{B}(42-61)$ & 2 & 48 & 50 & 25 & 70 & 5 & 1,2 \\
\hline $\mathrm{B} / \mathrm{A}(61-78)$ & 3 & 51 & 54 & 21 & 75 & 4 & 1,2 \\
\hline B1 (78 - 99) & 1 & 54 & 55 & 19 & 77 & 4 & 1,2 \\
\hline B2 $(99-140)$ & 1 & 53 & 54 & 20 & 75 & 5 & 1,2 \\
\hline \multicolumn{8}{|c|}{ Nitossolo Háplico (Pi 3a e EF) } \\
\hline $\mathrm{A} 1(0-16)$ & 11 & 42 & 53 & 34 & 58 & 8 & 0,9 \\
\hline A2 $(16-38)$ & 9 & 46 & 55 & 33 & 60 & 7 & 1,2 \\
\hline $\mathrm{A} / \mathrm{B}(38-56)$ & 2 & 48 & 50 & 29 & 64 & 7 & 1,2 \\
\hline $\mathrm{B} / \mathrm{A}(56-82)$ & 4 & 50 & 54 & 22 & 73 & 5 & 1,2 \\
\hline B1 (82 - 102) & 4 & 51 & 55 & 20 & 75 & 5 & 1,2 \\
\hline B2 $(102-140)$ & 1 & 53 & 54 & 21 & 76 & 5 & 1,2 \\
\hline
\end{tabular}

Pi10m: pinus com 10 meses de idade; Pi26a: pinus com 26 anos de idade; CN: campo nativo; EF: estrada florestal; Pi3a: pinus com três anos de idade.

Dentro da área da parcela experimental instalada na estrada, foram coletadas, em um único local, amostras do solo deformadas, para determinar algumas características físicas e químicas do solo, cujos valores encontram-se na tabela 2. A distribuição de tamanho e estabilidade dos agregados estáveis em 
água (DMP e DMG) foi feita pelo método de Kemper e Cheppil (1965). Para determinar matéria orgânica, pH em água, alumínio trocável e capacidade de troca de cátions do solo, seguiu-se a metodologia recomendada por TEDESCO et al. (1995).

Tabela 2. Valores de diâmetro médio ponderado (DMP) e geométrico (DMG), matéria orgânica (MO), pH em água 1:1, alumínio trocável (Al), capacidade de troca de cátions (CTC), da camada superficial do solo.

Table 2. Weighted average diameter values (DMP) and average geometric diameter values (DMG) organic material (MO), water $\mathrm{pH}$ 1:1, changeable aluminum (Al), capacity of cations exchange (CTC), of the superficial layer of soils.

\begin{tabular}{|c|c|c|c|c|c|c|c|}
\hline \multirow{2}{*}{ Tratamento } & \multirow{2}{*}{$\begin{array}{c}\text { Camada } \\
\mathbf{c m}\end{array}$} & DMP & DMG & \multirow{2}{*}{$\begin{array}{c}\text { MO } \\
\%\end{array}$} & \multirow{2}{*}{$\begin{array}{c}\text { pH (água) } \\
1: 1\end{array}$} & \multirow{2}{*}{\multicolumn{2}{|c|}{ Al $\mathrm{cmol}_{\mathrm{c}} \cdot \mathrm{dm}^{-3}$}} \\
\hline & & --- & 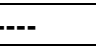 & & & & \\
\hline \multirow[t]{4}{*}{ Pi10m } & $0-5$ & 5,45 & 4,75 & 5,4 & 4,4 & 5,0 & 8,4 \\
\hline & $5-10$ & 5,91 & 5,36 & 5,5 & 4,3 & 5,2 & 8,3 \\
\hline & $10-15$ & 5,74 & 5,33 & 4,9 & 4,2 & 6,2 & 7,8 \\
\hline & $15-20$ & 6,02 & 5,73 & 5,0 & 4,2 & 6,5 & 7,8 \\
\hline \multirow[t]{4}{*}{ Pi26a } & $0-5$ & 6,07 & 5,68 & 11,2 & 4,3 & 3,9 & 7,7 \\
\hline & $5-10$ & 5,94 & 5,51 & 3,8 & 4,5 & 4,7 & 6,6 \\
\hline & $10-15$ & 5,91 & 5,59 & 4,1 & 4,3 & 4,6 & 5,3 \\
\hline & $15-20$ & 5,61 & 5,07 & 3,8 & 4,3 & 4,9 & 6,1 \\
\hline \multirow[t]{4}{*}{$\mathrm{CN}$} & $0-5$ & 5,77 & 5,01 & 7,0 & 4,1 & 2,9 & 6,1 \\
\hline & $5-10$ & 6,08 & 5,76 & 5,4 & 4,4 & 3,8 & 5,4 \\
\hline & $10-15$ & 6,08 & 5,83 & 4,6 & 4,4 & 4,5 & 5,9 \\
\hline & $15-20$ & 5,94 & 5,43 & 4,6 & 4,7 & 4,3 & 6,1 \\
\hline \multirow[t]{4}{*}{ EF } & $0-5$ & 5,72 & 5,24 & 3,4 & 4,4 & 4,9 & 6,4 \\
\hline & $5-10$ & 3,89 & 2,87 & 3,1 & 4,3 & 5,2 & 6,3 \\
\hline & $10-15$ & 2,91 & 1,84 & 2,5 & 4,2 & 4,1 & 5,0 \\
\hline & $15-20$ & 2,96 & 1,88 & 2,7 & 4,2 & 4,3 & 5,6 \\
\hline \multirow[t]{4}{*}{ Pi3a } & $0-5$ & 6,00 & 5,57 & 7,3 & 4,5 & 0,9 & 13,2 \\
\hline & $5-10$ & 5,96 & 5,67 & 5,3 & 4,9 & 1,9 & 8,6 \\
\hline & $10-15$ & 6,01 & 5,65 & 4,8 & 4,7 & 2,6 & 8,3 \\
\hline & $15-20$ & 5,76 & 5,26 & 4,3 & 4,8 & 4,8 & 7,1 \\
\hline
\end{tabular}

Pi10m: pinus com 10 meses de idade; Pi26a: pinus com 26 anos de idade; CN: campo nativo; EF: estrada florestal; Pi3a: pinus com três anos de idade.

Para instalação das parcelas, procedeu-se do seguinte modo: drenos foram construídos na cabeceira e nas laterais das parcelas, com o objetivo de isolar a área útil das mesmas do restante da área experimental. Na parte inferior, em formato de "V", a parcela foi isolada com pranchas que conduziam a enxurrada para dentro de uma calha coletora, a Roda Coshocton, situada na parte mais baixa do terreno. Na cabeceira da parcela IV (EF), o isolamento foi melhorado na sua parte mais alta, com a colocação de uma prancha de madeira associada ao dreno. Com isso, desviou-se o excedente de enxurrada que provinha da parte superior da estrada e evitou-se que o escoamento superficial de dentro da parcela saísse da mesma.

A quantificação do volume de chuva nos locais das parcelas foi feita colocando-se três coletores a céu aberto (pluviômetros), distribuídos na área experimental de maneira a registrarem o volume de chuva precipitado nas cinco parcelas, do seguinte modo: um coletor situado ao lado da parcela I (Pi10m), que registrava o volume de chuva nesta parcela; outro coletor situado ao lado da parcela III (CN), que registrava o volume de chuva nesta parcela; o volume de chuva da parcela II (Pi26a) era estimado pela média aritmética dos volumes registrados nas parcelas I e III; e outro coletor situado ao lado da parcela IV (EF), que registrava o volume de chuva nesta parcela e na parcela V (Pi3a).

Para a coleta de água e sedimentos decorrentes do escoamento superficial, usou-se uma calha coletora denominada "Roda Coshocton", colocada ao final da pendente de cada parcela e conectada por meio de uma mangueira a um recipiente de coleta, de plástico com tampa, com capacidade para 60 litros de água. A roda é constituída de uma calha coletora e de uma roda divisora de enxurrada, a qual foi 
desenvolvida pelo Departamento de Agricultura dos EUA (PARSON, 1954). O equipamento coleta 1\% da enxurrada ocorrida na área e incidente sobre o conjunto calha e roda. A coleta de enxurrada foi realizada semanalmente, respeitando-se o final das precipitações acumuladas no período semanal.

As perdas de água por escoamento superficial foram determinadas pelo valor da medição direta do volume coletado pela Roda Coshocton, multiplicado por 100. Media-se a altura da lâmina de enxurrada contida no recipiente coletor, com o auxílio de uma régua graduada, no centro do recipiente. $\mathrm{O}$ volume de enxurrada contido no recipiente foi obtido multiplicando-se a altura da lâmina pelo diâmetro do referido recipiente. Para as perdas de solo, era realizada a coleta de amostra dos sedimentos no recipiente e sobre a calha da Roda Coshocton, separadamente. Para os sedimentos contidos no recipiente, após a retirada do excesso de água, os sedimentos úmidos eram pesados. Os sedimentos depositados no leito da Roda Coshocton eram coletados com auxílio de uma espátula e pesados. Uma amostra úmida dos sedimentos (do recipiente e da roda) era coletada para determinação da umidade gravimétrica. Em laboratório, essa amostra era seca em estufa a $60{ }^{\circ} \mathrm{C}$, para correção das perdas de solo para base seca. $\mathrm{O}$ valor da massa de solo perdida e contida no recipiente coletor era multiplicada por 100, para corrigi-la em relação ao percentual coletado pela roda. A perda total de solo foi obtida pela soma da massa seca dos sedimentos da calha coletora e do recipiente coletor.

\section{RESULTADOS E DISCUSSÃO}

Durante o período experimental (17 meses), a precipitação foi de $2.040 \mathrm{~mm}$ de chuva, na média dos locais onde se situavam as parcelas, cujos valores variaram de $1.935 \mathrm{~mm}$ a $2.103 \mathrm{~mm}$ entre um local e outro (Tabela 3). Essa precipitação média foi, portanto, equivalente a $1.440 \mathrm{~mm}$ de chuva estimada para o ano. Assim, essa precipitação média, estimada para o ano, foi $20 \%$ menor do que os $1.800 \mathrm{~mm}$ anuais que normalmente precipitam, em média, na região (GOVERNO DE SC, 2013). A variação de $170 \mathrm{~mm}$ de chuva entre a maior e a menor altura de chuva precipitada nos locais das parcelas foi normal e se deve às distâncias entre os mesmos. O tratamento pinus com 10 meses (Pi10m), por exemplo, instalado na parcela I, ficava a uma distância maior do que $30 \mathrm{~km}$ do pinus com três anos (Pi3a), instalado na parcela $\mathrm{V}$.

Tabela 3. Valores de altura de chuva e de perdas de solo e água, em pinus de diferentes idades, campo nativo e estrada florestal, entre setembro de 2009 e janeiro de 2011, nos tratamentos estudados.

Table 3. Rain, rainfall and soil losses values in different ages of pinus, grassland and forestry roads, from September 2009 to January 2011.

\begin{tabular}{lccccc}
\hline \multirow{2}{*}{ Tratamento } & \multirow{2}{*}{ Parcela } & $\begin{array}{c}\text { Altura de chuva } \\
\mathbf{~ m m}\end{array}$ & $\begin{array}{c}\text { Perda de solo kg } \\
\text { ha }^{-\mathbf{1}}\end{array}$ & \multicolumn{2}{c}{ Perdas de água } \\
\hline Pi3a & 5 & 2.103 & 08 & $\mathbf{m m}$ & \% da chuva \\
CN & 3 & 2.060 & 28 & 06 & 0,3 \\
Pi26a & 2 & 1.997 & 40 & 13 & 0,6 \\
Pi10m & 1 & 1.935 & 74 & 157 & 7,9 \\
EF & 4 & 2.103 & 22.000 & 928 & 1,2 \\
\hline
\end{tabular}

Pi3a: pinus com três anos de idade; CN: campo nativo; Pi26a: pinus com 26 anos de idade; Pi10m: pinus com 10 meses de idade; EF: estrada florestal.

Os valores de perda de solo nas parcelas reflorestadas de pinus (Tabela 3) podem ser considerados baixos do ponto de vista de seu efeito de degradação do solo, quando comparados aos valores de tolerância de perda de solo previstos no trabalho de Bertol e Almeida (2000) para os solos do local de estudo. Os resultados podem ser explicados pelo efeito combinado dos diversos fatores que influenciam a erosão hídrica, entre os quais a cobertura do solo pelo dossel das plantas e a cobertura do solo pela serapilheira (CAMARGO CORRÊA, 2009). Assim, as duas formas de cobertura do solo decorrentes da floresta interceptaram as gotas da chuva e evitaram a desagregação do solo e o transporte de sedimentos. Além disso, essas condições de cobertura e o efeito das árvores no solo favoreceram a infiltração da maior parte da água no solo. As diferentes idades dos pinus ofereceram diferentes graus de cobertura pelo dossel e diferentes quantidades de serapilheira sobre o solo. No caso do pinus com 26 anos (Pi26a), apesar da baixa densidade de árvores, muito menor do que no Pi3a, a baixa perda de solo foi resultante exatamente do efeito da cobertura do solo proporcionada pela 
serapilheira acumulada durante todo o tempo de crescimento da floresta. No caso do Pißa, as árvores já ofereciam cobertura de praticamente $100 \%$ da superfície do solo e, ainda, a massa de serapilheira acumulada também já era expressiva. O Pi10m, por outro lado, apresentava baixa cobertura pelo dossel e praticamente nenhuma massa de serapilheira, motivo pelo qual apresentou perdas de solo maiores, entre as parcelas de reflorestamento, apesar de o solo estar parcialmente coberto com vegetação espontânea e ainda conter, na superfície do solo, restos de madeira do cultivo anterior de pinus.

As perdas de solo verificadas no tratamento campo nativo (CN) foram também muito baixas, com valores semelhantes aos verificados nos tratamentos com pinus (Tabela 3). Dados semelhantes foram encontrados por Bertol et al. (2011), que trabalharam com quantificação de erosão sob chuva simulada em campo nativo sobre um solo semelhante. Essas baixas perdas de solo em campo nativo, segundo Bortolozo (2010), se devem ao efeito da massa vegetal da parte aérea do campo, que retarda o contato entre a água e o solo, aumentando a infiltração no solo e diminuindo o escoamento superficial.

A estrada florestal (EF) apresentou perdas de solo 587 vezes maiores do que a média dos tratamentos com pinus e campo nativo, embora a altura de chuva tenha sido praticamente igual nos locais desses tratamentos (Tabela 3). As 22 t.ha $^{-1}$ de solo perdido por erosão na estrada, durante os 17 meses de experimento, permitem estimar uma perda anual de solo de 15,5 t.ha ${ }^{-1}$. Esse valor é considerado alto para o solo em questão, cujo limite tolerável é de 12 t.ha ${ }^{-1}$.ano ${ }^{-1}$, segundo Bertol e Almeida (2000). Em áreas de reflorestamento, Neary e Hornbeck (1994) estimam que mais de 90\% da produção de sedimentos são provenientes de estradas para colheita florestal. No entanto, os valores de perdas de solo no tratamento EF foram substancialmente menores do que os valores normalmente verificados em solo sem cultivo e descoberto, sob condição de parcela em experimento de erosão hídrica, segundo Amaral et al. (2008). Mesmo assim, as perdas de solo quantificadas no tratamento EF preocupam do ponto de vista ambiental, uma vez que os sedimentos perdidos dessas estradas alcançam normalmente mananciais de água de superfície, tais como rios e represas, causando contaminação e assoreamento, reduzindo a vida útil dos mesmos.

Em relação às perdas de água por escoamento superficial, foram muito baixas nos tratamentos com pinus, com valores levemente mais altos no Pi26a (Tabela 3). Neste tratamento, as perdas de água, equivalentes a 7,9\% da altura de chuva precipitada, foram superestimadas, devido ao fato de a calha coletora (Roda Coshocton) ter sido instalada em uma posição na pendente do terreno onde ocorria interfluxo e, com isso, mantinha ativo o escoamento superficial mesmo depois de cessada a precipitação. No tratamento Pi10m, o escoamento superficial foi equivalente a 1,2\% da precipitação, portando, duas vezes maior do que no tratamento Pi3a, devido à baixa cobertura do solo pelo dossel das plantas, apesar da existência de cobertura parcial da superfície do solo por plantas espontâneas. As perdas de água verificadas no $\mathrm{CN}$ foram também muito baixas, justificadas pelo exposto anteriormente, quando da discussão dos dados de perdas de solo, e de acordo com dados observados por Bertol et al. (2011). Dessa forma, observa-se a eficácia do uso do solo, tanto por florestas plantadas quanto por campo nativo, na redução das perdas de solo e de água por erosão hídrica em relação ao solo usado como estrada de uso florestal.

No tratamento EF, as perdas de água por escoamento superficial foram altas quando comparadas à altura de chuva precipitada, equivalendo a 44\% (Tabela 3). Isso revela a necessidade de controle do escoamento superficial sobre o leito dessas estradas, pois a enxurrada, nessas condições, alcança elevada velocidade, devido ao grande volume, e com isso transporta, conforme já mencionado, sedimentos para os mananciais de água de superfície.

Nas figuras 1, 2, 3, 4 e 5, são apresentadas as relações entre os seguintes dados: perdas de água versus altura de chuva, perdas de solo versus altura de chuva e perdas de solo versus perdas de água, nos tratamentos pinus com 10 meses (Pi10m), pinus com 26 anos (Pi26a), campo nativo (CN), estrada florestal (EF) e pinus com três anos (Pi3a), respectivamente.

Os valores de perda de água relacionaram-se de maneira positiva e significativa com os de altura de chuva, em todos os tratamentos. Isso é justificado pelo fato de que o solo apresenta um limite de infiltração de água, segundo Kohnke (1968), e, por isso, mesmo sob condições de usos e manejos diferentes, quanto maior a altura da chuva, maior é o escoamento superficial. Essa justificativa suporta as regressões lineares positivas entre esses dados nas figuras 1, 2, 3, 4 e 5. Portanto, mesmo em condições de sistemas de uso e manejo do solo que potencializem a infiltração de água, como é o caso do reflorestamento e de campo nativo, as chuvas de maior volume são capazes de propiciar escoamentos superficiais relativamente elevados que, por isso, necessitam ser controlados. 

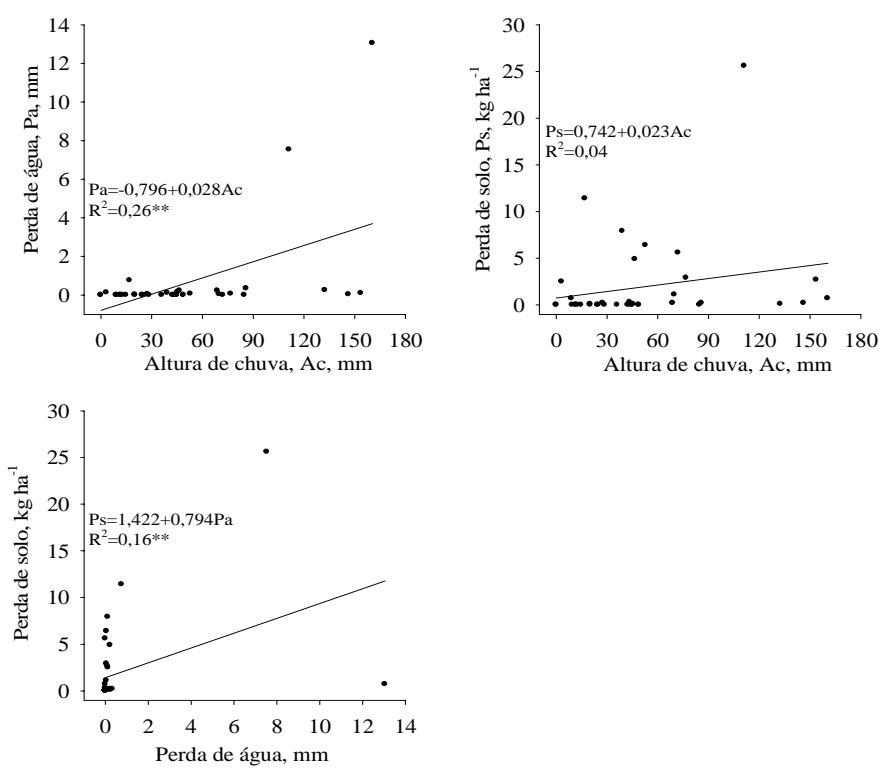

Figura 1. Relação de perda de água (Pa) com altura de chuva (Ac), perda de solo (Ps) com altura de chuva (Ac) e perda de solo (Ps) com perda de água (Pa) no tratamento pinus com 10 meses de idade (Pi10m). ** Significativo a $1 \%$.

Figure 1. Relation among water lost $(\mathrm{Pa})$ with rain height $(\mathrm{Ac})$, soil lost (Ps) with rain height (Ac) and soil lost (Ps) with water lost (Pa) from pinus with 10 months. **Significant at $1 \%$.
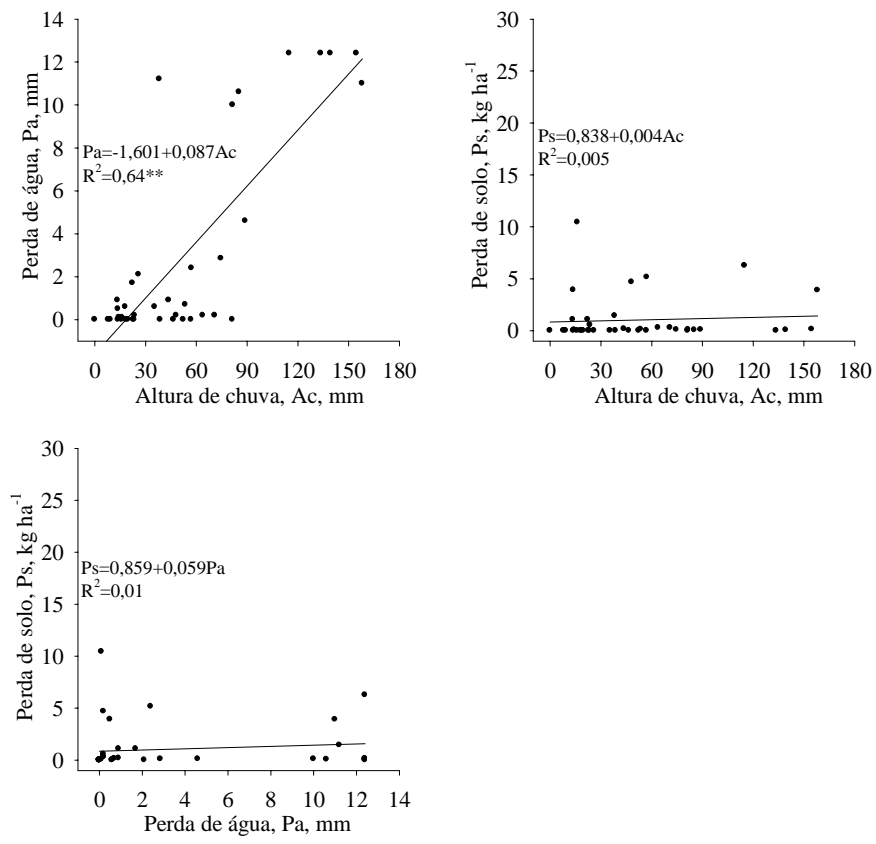

Figura 2. Relação de perda de água (Pa) com altura de chuva (Ac), perda de solo (Ps) com altura de chuva (Ac) e perda de solo (Ps) com perda de água (Pa) no tratamento pinus com 26 anos de idade (Pi26a). ** Significativo a $1 \%$.

Figure 2. Relation among water lost (Pa) with rain height (Ac), soil lost (Ps) with rain height (Ac) and soil lost (Ps) with water lost $(\mathrm{Pa})$ from pinus with 26 years. ${ }^{* *}$ Significant at $1 \%$. 

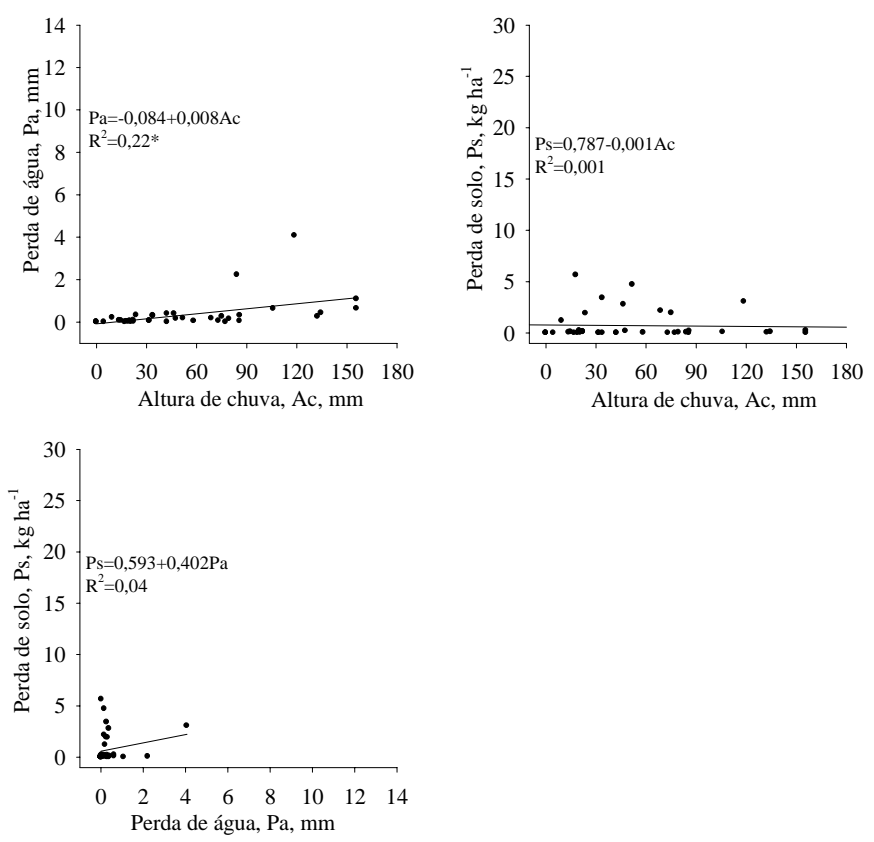

Figura 3. Relação de perda de água (Pa) com altura de chuva (Ac), perda de solo (Ps) com altura de chuva (Ac) e perda de solo (Ps) com perda de água (Pa) no tratamento campo nativo (CN). * Significativo a $5 \%$.

Figure 3. Relation among water lost (Pa) with rain height (Ac), soil lost (Ps) with rain height (Ac) and soil lost (Ps) with water lost (Pa) from grassland. *Significant at 5\%.
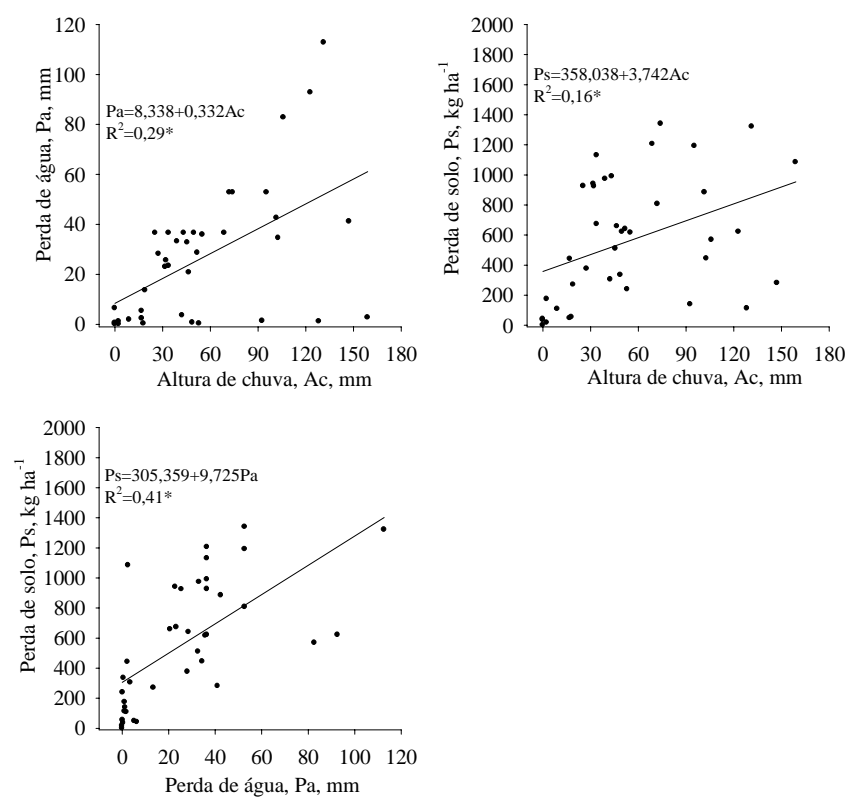

Figura 4. Relação de perda de água (Pa) com altura de chuva (Ac), perda de solo (Ps) com altura de chuva (Ac) e perda de solo (Ps) com perda de água (Pa) no tratamento estrada florestal (EF). * Significativo a $5 \%$.

Figure 4. Relation among water lost (Pa) with rain height (Ac), soil lost (Ps) with rain height (Ac) and soil lost (Ps) with water lost (Pa) from forestry road. * Significant at $5 \%$. 

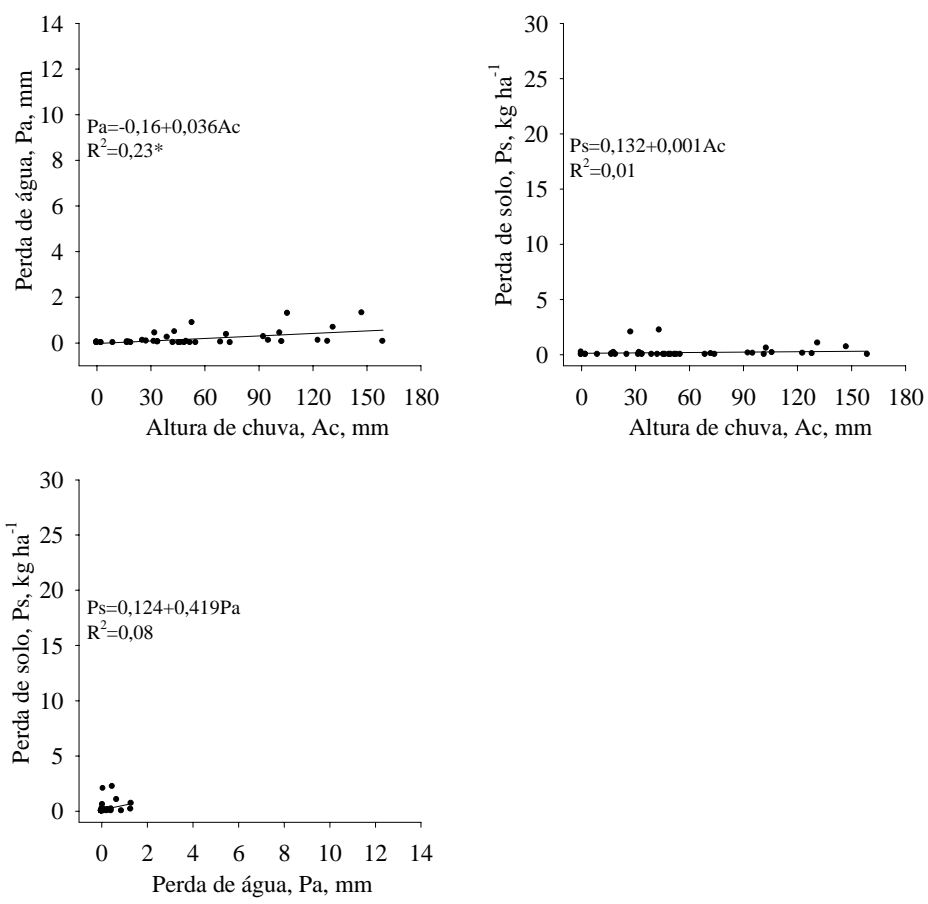

Figura 5. Relação de perda de água (Pa) com altura de chuva (Ac), perda de solo (Ps) com altura de chuva (Ac) e perda de solo (Ps) com perda de água ( $\mathrm{Pa}$ ) no tratamento pinus com três anos (Pi3a). * Significativo a 5\%.

Figure 5. Relation among water lost (Pa) with rain height (Ac), soil lost (Ps) with rain height (Ac) and soil lost (Ps) with water lost (Pa) from pinus with 03 years. *Significant at $5 \%$.

No caso das relações entre os dados de perda de solo e de altura de chuva, elas foram significativas apenas no tratamento EF. Nesse caso, a EF, apesar da dispersão dos dados no gráfico (Figura 4), houve significância na relação das variáveis. Isso é justificado pelo fato de que, nessa condição de uso e manejo do solo, a superfície foi permanentemente mantida descoberta e sujeita à ação dos eventos de chuva e escoamento superficial associado, conforme verificado em outros trabalhos (SCHICK et al., 2013). Portanto, nessas condições, a chuva e a enxurrada associada permanentemente expressam sua energia erosiva sobre a superfície do solo descoberto. Com isso, as perdas de solo são sempre dependentes dessa energia.

A relação entre os dados de perdas de solo e perdas de água foi positiva, mas significante apenas nos tratamentos Pi10m (Figura 1) e EF (Figura 4). Nos demais tratamentos, a maioria dos dados de perdas de solo foi extremamente baixa, mesmo em eventos de perdas de água relativamente altos, o que tornou a relação não significativa. Isso é normal em situações em que o uso do solo oferece ampla proteção ao mesmo contra a energia erosiva da chuva e enxurrada e, ainda, potencializa a infiltração de água no solo pelo seu efeito sobre as propriedades físicas, como foi o caso dos tratamentos Pi26a (Figura 2), CN (Figura 3) e Pi3a (Figura 5).

\section{CONCLUSÕES}

- A erosão hídrica foi muito baixa nos diversos tratamentos estudados, com exceção da estrada de uso florestal, onde as perdas de solo foram de 22 t.ha $^{-1}$ e as de água de $44 \%$ da chuva, consideradas muito altas.

- As perdas de água na forma de enxurrada relacionaram-se positiva e significativamente com a altura de chuva em todas as situações estudadas. As perdas de solo apresentaram essa mesma relação com a altura de chuva na estrada florestal, enquanto que, com as perdas de água, essa relação das perdas de solo ocorreu nos tratamentos pinus com 10 meses e estrada florestal. 


\section{REFERÊNCIAS}

ASSOCIAÇÃO CATARINENSE DE EMPRESAS FLORESTAIS (ACR). Disponível em: < http://www. acr.org.br/noticias/>. Acesso em: 26 de janeiro de 2008.

AMARAL, A. J.; BERTOL, I.; COGO, N. P.; BARBOSA, F. T. Redução da erosão hídrica em três sistemas de manejo do solo em um Cambissolo Húmico da região do Planalto Sul-Catarinense. Revista Brasileira de Ciência do Solo, Viçosa, MG, v. 32, n. 5, p. 2145 - 2155, 2008.

BERTOL, I.; ALMEIDA, J. A. Tolerância de perda de solo por erosão para os principais solos do estado de Santa Catarina. Revista Brasileira de Ciência do Solo, Viçosa, MG, v. 24, n. 3, p. 657 - 668, 2000.

BERTOL, I.; GOBBI, E.; BARBOSA, F. T.; FERREIRO, J. P.; GEBLER, L.; RAMOS, J. C.; WERNER, R. S. Erosão hídrica em campo nativo sob diversos manejos: perdas de água e solo e de fósforo, potássio e amônio na água de enxurrada. Revista Brasileira de Ciência do Solo, Viçosa, MG, n. 35, p. 1421 1430, 2011.

BORTOLOZO, F. R. Retenção de água, sedimento e nutrientes em faixas vegetadas de campo nativo na região dos campos gerais do Paraná. 61 f. Dissertação (Mestrado em Ciência do Solo) Universidade Federal do Paraná (UFPR), Curitiba, 2010.

CAMARGO CORRÊA, C. M.; DEDECECK, R. A. Erosão real e estimada através da rusle em estradas de uso florestais, em condições de relevo plano a suave ondulado. Floresta, Curitiba, PR, v. 39, n. 2, p. 381 - 391, 2009.

CARPENEDO, V.; MIELNICZUK, J. Estado de agregação e qualidade dos agregados de Latossolos roxos, submetidos a diferentes sistemas de manejo. Revista Brasileira de Ciência do Solo, Viçosa, MG, n. 14, p. 99 - 105, 1990.

CAVICHIOLO, S. R. Perdas de solo e nutrientes por erosão hídrica em diferentes métodos de preparo do solo em plantio de Pinus taeda. 152 f. Tese (Doutorado em Ciências Florestais) Universidade Federal do Paraná (UFPR), Curitiba, 2005.

GEE, G. W.; BAUDER, J. W. Particle-size analysis. In: KLUTE, A. Methods of soil analysis. American Society of Agronomy, Madison, 1986. p. 383 - 411.

GOVERNO DO ESTADO DE SANTA CATARINA. Disponível em: <http://www.campobelodosul.sc. gov.br/>. Acesso em: 02/02/2013.

KEMPER, W. D.; CHEPIL, W. S. Size distribution of aggregates. In: BLACK, C. A.; KOHNKE, H. Soil Physics. New York: McGraw-Hill. 1968. 224 p.

KOEPPEN, W. Climatologia: un studio de los climas de la tierra. Fondo de Cultura Economica, Mexico. 1948. 478 p.

NEARY, D. G.; HORNBECK, J. W. Impacts of harvesting and associated practices on off-site environmental quality. In: _ Impacts of forest harvesting on long-term site productivity. Londres: Chapman and Hall, 1994. c. 4, p. 81 - 119.

PARSONS, D. A. Coshocton - Type runoff samplers. Washington, DC: Laboratory investigations. United States Department of Agriculture. Soil Conservation Service, 1954. 16 p.

PYE, J. M.; VITOUSEK, P. M. Soil and nutrients removals by erosion and windrowing at a Southeastern, U.S. Piedmont site. Forest Ecology and Management, Philadelphia, 1985. v. 11, p. 145 - 155.

SCHICK, J.; BERTOL, I. Erosão hídrica sob chuva natural em experimento de longa duração no sul do Brasil. Revista Brasileira de Ciência do Solo, Viçosa, MG. 2013. (Em análise).

STOLLE, L.; LINGNAU, C.; ARCE, J. E. Mapeamento da fragilidade ambiental em áreas de plantios florestais. In: XIII SIMPÓSIO BRASILEIRO DE SENSORIAMENTO REMOTO, 2007, Florianópolis. Anais do... Florianópolis, 2007. p. 1871 - 1873.

TEDESCO, J. M. Nitrogênio. In: GIANELLO, C.; BISSANI, C. A.; TEDESCO, J. M. Princípios de Fertilidade do Solo. Porto Alegre: Departamento de Solos da UFRGS, 1995. 174 p. 